\title{
Difusión popular de las ciencias sociales
}

\author{
Eva Salgado Andrade
}

E

uso que se hace de los medios de información masiva, para convertirlos en instrumento de manipulación y de transmisión de valores culturales ajenos a nuestra realidad, obliga a reflexionar en torno a la necesidad de una comunicación alternativa. Afortunadamente, la discusión no es nueva ni estéril y como fruto de ella pueden constatarse varios esfuerzos ya consolidados para poner en práctica nuevos programas que representen una importante opción frente al panorama actual.

Sin embargo, las impugnaciones aún no se han agotado. pues quedan varios puntos por mejorar. Una de las causas que contribuyen al fracaso de los proyectos alternativos es que se ha descuidado el aspecto del contenido, pues algunos comunicadores piensan que el mero hecho de recurrir a técnicas novedosas, que permitan la participación del público, puede considerarse una opción. No hay que olvidar que un punto esencial para contribuir a la solución de los problemas sociales es, precisamente, el análisis de tales problemas. Por lo tanto, entre los principales responsables de proponer el contenido que debe transmitir la comunicación se encuentran los científicos sociales.

La actividad de los científicos sociales podría resumirse como un compromiso por aprehender y comprender el pasado y el presente, evaluarlos $y$. a partir de ahí, proponer los cambios que hagan más habitable el entorno. A lo largo de estas tareas, no debe descuidarse el aspecto de la difusión de los conocimientos adquiridos a fin de que se conviertan en auténticos aportes para la sociedad de la cual emanan.

Las ideas anteriores, combinadas con el concepto de comunicación alternativa, podrían condensarse bajo la noción de un sentido popular de las ciencias sociales. Existe en la actualidad una tendencia a exaltar el sentido de lo popular; constantemente se ponen en marcha proyectos de cultura popular. se han creado museos y exposiciones de cultura popular, se habla de la necesidad de una educación popular, etc. Este auge de lo popular, más que una moda intelectual pasajera, representa la exigencia de la sociedad en su conjunto por compartir los frutos de la actividad intelectual del hombre, ya sea a través del arte o de las ciencias.

El sentido de lo popular ha de entenderse en dos direcciones. Por una parte, se supera el concepto de las elites como los actores determinantes en la evolución social. No hay grupos sociales más importantes que otros, ni manifestaciones culturales privilegiadas; las ciencias sociales se vuelven más democráticas - valga la expresión -, libres de prejuicios culturales. Por otra parte, los resultados que se obtienen a través de las ciencias sociales emprenden el retorno a la sociedad que los origina. Los científicos sociales se convierten en un puente de unión que permite a los miembros de una sociedad conocerse más a sí mismos y actuar en conjunto para su superación.

Al hablar de un sentido. popular de las ciencias sociales, uno se coloca en un plano donde ya no cabe la especialización de actividades. El compromiso ya no es de unos cuantos individuos, e intervienen por igual historiadores, $\mathrm{fi}$ lósofos, economistas, psicólogos, pedagogos, comunicadores, unidos por un objetivo común: contribuir a la educación para el cambio, entendida ésta como un proceso permanente y socialmente participativo y democrático. 
Ahora bien, uno de los puntos sobre los que debe recaer la discusión en torno al sentido popular de las ciencias sociales son los medios de difusión, tanto masivos como interpersonales; si se saben emplear, constituyen canales para que la sociedad sea depositaria de los conocimientos que le son indispensables para la superación de sus problemas.

La difusión ha sufrido importantes evoluciones, siempre en estrecha relación con el grado de desarrollo tecnológico. La transmisión de los conocimientos se ha realizado a través de medios tan diversos como las pinturas en cavernas o los libros manuscritos por pacientes monjes. No hay que olvidar que ya han surgido medios tan sofisticados como la televisión por cable, o los procesos electrostáticos de reproducción, los sistemas electrónicos de impresión rápida, las computadoras, etc. Pero antes de elucubrar con los por ahora no tan accesibles medios de difusión, es pertinente emprender una revisión de los medios que, en mayor o menor medida, pueden facilitar la difusión popular.

\section{Medios impresos:}

a) Periódicos: nuestro país cuenta con una amplia gama de periódicos especializados $y$ de información general, de variados tonos $y$ tendencias. Dentro de este conglomerado es posible encontrar espacio para la difusión de la cultura, donde tendrían lugar los aportes de las ciencias sociales. La importancia que en cada periódico se otorga a la cultura depende de la política editorial de la empresa; en algunos, la cultura cuenta con una sección especial y permanente, en tanto que en otros las ciencias sociales y sus aportes son sustancialmente transformados en acontecimiento sociales, comparables a una boda o al lanzamiento de un nuevo artista.

Son varios los problemas por aclarar en torno a la prensa y la cultura; un periodista español señala algunas interrogantes: "¿Debe la cultura tener presencia como tal en la prensa o debe reducirse a la condición de noticia? ¿Debe estar a cargo de especialistas en cada materia (expertos) o de especialistas en información (periodistas)? ¿Debe enjuiciar el objeto cultural o formar al lector?"'

Conforme a lo que se ha esbozado en líneas anteriores, un sentido popular de las ciencias sociales, al ser expresado a través de la prensa, serviría para la elaboración de prácticamente todos los géneros periodisticos: artículos de fondo, reportajes, crónicas, entrevistas, en fin, que estarían impregnados de los resultados de la investigación social y, por lo tanto, sus contenidos arrojarían soluciones a los problemas sociales. Por lo tanto. los científicos sociales deben pugnar por conseguir espacios en la prensa y, sobre todo, deben colaborar con los periodistas. La tarea, por supuesto, no es fácil, pues implica una feroz competencia con otros temas (nota roja, deportes, espectáculos) que gozan de mayor demanda.

Por último, hay que hacer notar que la prensa desempeña un papel vital para dar a conocer otras formas de difusión, tales como conferencias, mesas redondas y seminarios.

b) Revistas: este medio ofrece grandes posibilidades para la difusión de la materia que nos ocupa. Aun cuando en las revistas imperan condiciones similares a las de la prensa - comercialización de la información o trata-

' Iván Tubau, Teoría y práctica del periodismo cu/tural, Barcelona, ATE, 1982, p. 15. 
miento superficial de la cultura -, hay que señalar, de manera primordial, a las revistas especializadas. Patrocinadas por universidades, institutos 0 editoriales, esta clase de revistas constituyen una importante opción para contribuir a formar opinión sobre nuestros problemas y consecuentemente, al cambio. En sus páginas pueden tratarse, ya sea en forma de ensayos, artículos, reportajes, etc., los resultados de la investigación social. Cabe mencionar que las revistas son medios idóneos para el intercambio de conocimientos pues dan la información de una manera rápida y con cierta profundidad.

c) Libros: han logrado sustraerse en gran medida del enfoque comercial que orienta a otros canales de difusión. Gozan, además, de las siguientes ventajas: no tienen límite en la superficie que destinan a un tema, ni mayores presiones en el tiempo de elaboración e impresión; son fáciles de conservar y de consultar y. hasta hace poco tiempo, de adquisición relativamente sencilla. Las ventajas que ofrecen pueden resistir los embates del avance tecnológico: "Bien es cierto que el libro resulta menos manejable y ocupa más lugar que otros sistemas de almacenamiento, pero hasta el momento ofrece unas posibilidades mucho más sencillas de utilización que, por ejemplo. el microfilm o el archivo magnetofónico."2

Los libros asumen diversas formas: antologías, diccionarios, enciclopedias, monografías, obras completas, etc. Bajo la forma que sea, hay que destacar aquellos libros considerados como de divulgación, entre los que se encuentran los libros de texto, dirigidos a públicos amplios y que recurren a formas de expresión accesibles a la mayoría. Por cierto, un libro de divulgación o un libro de texto deben ser "un pretexto para incitar a sus lectores a ir más allá, para despertar curiosidades malsanas, para ensuciar cabezas por dentro (...) un libro de texto que sólo sirve para aprobar exámenes se invalida a sí mismo como pretexto".. ${ }^{3}$

ch) Publicaciones varias: cuando se piensa en una comunicación alternativa para dar a las ciencias sociales un sentido popular, es válido crear nuevas opciones. No todo podrá difundirse a través de revistas o de libros, así pues pueden tenerse en mente otras formas más modestas: folletos. que pueden ser incluso ilustrados, boletines, volantes, carteles. La forma será lo de menos, siempre y cuando se tenga en cuenta el objetivo de fomentar la participación popular en torno al conocimiento y la solución de los problemas sociales.

\section{Medios electrónicos:}

d) Radio: "la Ley Federal de Radio y Televisión señala que una de las funciones de tales medios es contribuir a elevar el nivel cultural del pueblo o a conservar las características nacionales, las costumbres del país y sus tradiciones". 4 Estos objetivos llevan a suponer que tanto la radio como la televisión deben tener entre sus metas la difusión de las conciencias sociales. No obstante, el panorama radiofónico ofrece, tanto en AM como en FM, una abrumadora mayoría de estaciones comerciales, con espacios muy reducidos para la producción cultural en general, más aún para las ciencias sociales en particular.

2 Hans Magnus Enzensberger, Elementos para una teoria de los medios de comunicación. Barcelona, Anagrama, (3a. ed.), 1981, p. 65.

3 Iván Tubau, op. cit., p. 7.

- Raúl Cremoux, La legis/ación mexicana en radio y televisión. México. UAM-Xochimilco, 1982, p. 20. 
Existen, sin embargo, espacios valiosos en algunas estaciones que, con patrocinio gubernamental o universitario, han logrado sustraerse de la competencia comercial y destinar recursos a la producción de programas para una difusión popular de la ciencias sociales. Por otra parte, el Estado, al hacer uso del $12.5 \%$ que le corresponde en tiempo de transmisión, puede abrir nuevos canales. Para saber aprovecharlos, hay que tener en cuenta el gran alcance de la radio, capaz de llegar a zonas aisladas: deberá hacerse el mejor uso posible de los recursos sonoros, tales como la música o los efectos especiales, para proporcionar a los mensajes alternativos de radio no sólo el contenido, sino también la forma. Las posibilidades de formato son numerosas y van desde los reportajes, debates, programas de consultas al público, radionovelas (aunque a algunos les asuste el término).

e) Televisión: las condiciones en este medio, tanto desde el punto de vista legal como del uso excesivamente comercializado, son muy similares a las apuntadas para la radio. Hay que agregar que la televisión, si bien de un alcance más restringido, al contar con el elemento visual aumenta las posibilidades de difusión popular. La producción de programas televisivos, por otra parte, presenta mayores retos cuya solución no está al alcance de individuos aislados, sino que debe casi siempre realizarse a partir del apoyo institucional. Este medio puede constituirse en un foro para el análisis y solución de los problemas sociales a través de los diversos formatos: reportajes, entrevistas, programas de debate, películas, documentalese, inclusive, telenovelas.

f) Cine: dentro de los medios masivos, el cine funciona también como un importante canal para difundir la materia que nos ocupa. Si bien en la producción fílmica existe un marcado favoritismo para temas que sirven más bien como un escape a la realidad (amor, violencia, melodramas, aventuras). no ha de descartarse la producción basada en temas sociohistóricos o documentales. Por otro lado, no siempre será posible producir grandes películas. que ofrezcan competencia al cine comercial; la técnica cinematográfica puede ser empleada para fines más modestos y dar como fruto cortometrajes o documentales cuya exhibición no requiera grandes salas.

Además de los medios masivos, existen otros, llamados interpersonales, que aunque vayan dirigidos a públicos infinitamente más reducidos resultan vitales para la difusión popular de las ciencias sociales. Entre estos medios se encuentran los siguientes:

a) Conferencias y mesas redondas: en esencia, ambas actividades están orientadas por un fin común principal: reunir a un público interesado con uno o más especialistas en un tema o temas específicos. Si bien no logran atraer más que a pocas decenas de receptores (cantidad imperceptible en comparación con los millones de receptores de los medios masivos), resultan ventajosas para que los investigadores, o la institución que los apoya, tengan un estrecho contacto con el público: así, a la vez que se aclaran interrogantes, se nutren para proseguir con su labor científica.

b) Seminarios: comparten en gran medida las características de los dos medios anteriores, con la enorme ventaja de permitir - más bien exigir - la participación del público y, consecuentemente, una obligada retroalimentación, dicho en términos de comunicación. Esta clase de actividades se refuerza en muchas ocasiones con el estímulo de proporcionar a su público "constancias con valor a curriculum". Generalmente van dirigidas a público especializado, sin embargo deben aumentarse los esfuerzos por fomentar esta técnica de difusión en centros tan diversos como escuelas, fábricas, colonias, centros recreativos, etcétera.

c) Audiovisuales: este medio ofrece excelentes posibilidades pedagógi- 
cas que es, a fin de cuentas, lo que se persigue con una difusión popular. En vista de su relativamente sencilla producción y exhibición, permiten la difusión entre públicos numerosos y, a diferencia de la televisión, en horarios que el emisor juzgue prudentes para cada público específico.

ch) Museos: los museos no son, como algunos se inclinan a pensar, meros espacios de exhibición de objetos inertes, sino que constituyen canales fijos y permanentes para poner al público en contacto con la producción cultural, con lo cual se les permite conocer más la sociedad a la que pertenecen. Dentro de esta clasificación se incluyen las exposiciones que, al igual que los museos, abarcan una heterogénea gama de objetos con el fin de transmitir al público los conocimientos que posibilitan su participación en los problemas sociales: fotografías, objetos, documentos, etc., generalmente acompañados de textos explicativos. Por otra parte, debe combatirse la idea de los museos como recintos sagrados; por el contrario, un museo puede surgir a partir de espacios tan variados como parques, escuelas, casas o fábricas.

El panorama se amplía si consideramos que la difusión popular puede adoptar otras formas; por ejemplo. influir en la creación literaria y dar lugar a obras de teatro, novelas, cuentos o poesía con un claro contenido social. A través de esta camaleónica transformación, las ciencias sociales se despojan de los calificativos de oscuras e inexpugnables y llegan a públicos en apariencia poco interesados en los problemas sociales.

Mención aparte merece la seudo-difusión popular de las ciencias sociales. Amparados en la necesidad de preservar nuestros valores, no faltan astutos emisores que se encargan de transmitir telenovelas que recrean "lo más florido de la etapa porfirista", o fotonovelas a todo color donde entre la protagonista de algún hecho histórico y "Rarotonga" hay más que simples coincidencias.

Por último, es pertinente señalar que el avance furibundo de la ciencia abre cada día nuevas perspectivas de difusión; por ejemplo, el uso de videocaseteras o el auge de las computadoras. Sin embargo, en nuestro país todavia se ve lejano el día en que todo ciudadano tenga la opción de interrogar a su propia computadora acerca de los más recientes aportes de las ciencias sociales.

A primera vista, el panorama resulta halagador para que se realice la difusión popular de las ciencias sociales; sin embargo, no todo lo que brilla es oro: la politica comunicativa actual no parece darle sitio preferencial a esta rama. Así pues, hay que ser realistas y reconocer que son muchos los problemas y enorme la competencia para ganar dos o tres columnas en un periódico o en un programa cultural (no en horario triple A, por cierto). Pero la oportunidad puede surgir y hay que saber aprovecharla llegado el momento: mientras tanto, éstas son algunas propuestas que pueden contribuir a que las ciencias sociales lleven a cabo su cometido de permitir el análisis y la participación conjunta en los problemas que plantea la vida en sociedad:

No toda la difusión puede llevarse a cabo a través de los libros, considerados por algunos como idóneos para esta labor. Los científicos sociales no deben forzosamente esperar a escribir obras maestras que ameriten la publicación de un libro; antes bien, han de pensar en comunicar sus aportes de manera constante, bien sea bajo la forma de ensayos, artículos, pequeños libros de divulgación, reportajes, etc. Con ello, los resultados finales de toda investigación se verán enriquecidos y se formentará la participación popular.

Es imprescindible la cooperación entre los investigadores en ciencias sociales y los especialistas en comunicación. Los primeros aportarían nuevas ideas y conocimientos y los segundos contarian con un importante material 
para la elaboración de reportajes, documentales, guiones para radio y televisión, etc. Esta colaboración serviría para "encontrar técnicas de acceso, de formación. de presentación para todos estos hechos culturales (...). Procedimientos como la rescritura (rewriting), el fondo sonoro y la medición de inteligibilidad, pertenecen a estas técnicas de transformación".5

En ningún momento ha de menospreciarse el poder culturizador de los medios de información: "La enseñanza, en todo el mundo, está en crisis: la implosión de la información exige nuevos medios y nuevos métodos, se imponen planteamientos móviles. Los poderosos medios de comunicación de masas convierten en anacrónicos los métodos tradicionales de enseñanza."

Es aconsejable hacer uso de cualquier canal de difusión, sin descartarlo por prejuicios ideológicos: "En la difusión, todo sistema es válido. No hay medios 'malos'. estructuralmente descartables. Importa lo que a través de ellos circula." 7 El científico social debe luchar tenazmente por conseguir espacios para difundir nuevos conocimientos que permitan una auténtica participación de los receptores; de lo contrario se permitiría a quienes detentan el poder de los medios de información continuar con la invasión seudocultural. "Las horas que el niño pasa en la escuela sólo significa un momento de su vida, y sería rídiculo creer que ni en el mejor de los casos podrían contrarrestar la enseñanza infinitamente más tenaz y organizada de la calle, del cine. de la radio, del teatro, de la prensa." 8

Por otra parte, el investigador no siempre se verá favorecido con un espacio en los grandes medios; por lo tanto, debe también crear medios alternativos, tales como revistas o periódicos que, aunque de tirajes reducidos, sirvan como eficaces difusores. "El uso de los medios más sofisticados depende directamente del lugar que ocupen en una determinada formación social los procesos alternativos. A mayor espacio ganado por éstos, más acceso a los medios o mayor generación de sistemas de difusión propios. Cuando tales procesos se restringen, por manipulación o por represión, los mecanismos alternativos tienen un menor radio de acción: volantes, mantas, muros, periódicos o formas casi totalmente artesanales."9

Por último, hay que fomentar los medios interpersonales de difusión de las ciencias sociales, para así crear paulatinamente entre los receptores mayor interés en la materia. Por ejemplo, una mesa redonda o una conferencia, aun cuando no capten una audiencia mayor de 50 personas, cualitativamente puede ser más efectiva para concientizar sobre un problema social que un programa televisivo con millones de televidentes. Para ello, es necesario planear adecuadamente este tipo de actividades, realizarlas en lugares públicos -como parques o teatros populares-. hacerlas amenas para que generen mayor interés.

Habrá, sin duda, otros medios y técnicas de difusión no contemplados en las páginas anteriores. Será tarea de cada investigador dedicar de vez en cuando algo de tiempo a reflexionar al respecto $y$, más importante aún, llevarlo a la práctica.

5 Abraham A. Moles, "La radiotelevisión al servicio de la promoción sociocultural" en Jaime Goded. Lns medios de la comunicación colectiva. México. UNAM, Centro de Estudios de la Comunicación, 1976, p. 246.

- Décio Pignatari, Información, lenguaje, comunicación. Barcelona, Gustavo Gili, Col. Punto y Lírea, 1977, p. 63.

1 Daniel Prieto Castillo. Discurso autoritario y comunicación alternativa. México, Edicol, 1980. p. 14

B Aníbal Ponce, Educación y lucha de clases, México, Ediciones de Cultura Popular / Editorial Cartago, (6a. ed.). 1980, p. 227.

9 Daniel Prieto Castillo, op. cit., p. 14. 